\title{
HOMESCHOOLING NO BRASIL: CONSTITUCIONALIDADE E LEGALIDADE DO PROJETO DE LEI 3179/12
}

\section{HOMESCHOOLING IN BRAZIL: CONSTITUTIONALITY AND LEGALITY OF THE BILL 3179/12}

${ }^{1}$ Fabrício Veiga Costa

\section{RESUMO}

O movimento da educação domiciliar eclodiu nos Estados Unidos da América a partir da década de 60, influenciado por educadores considerados progressistas que levaram muitos pais escolherem educar seus filhos fora do sistema público de ensino. O projeto de Lei 3179 /12, de autoria do Deputado Lincoln Diniz Portela, propõe acrescentar um parágrafo no artigo 23 da Lei 9394/96 (Lei de Diretrizes e Base Nacional) para possibilitar a oferta domiciliar da educação básica. A análise da constitucionalidade do respectivo projeto de lei constitui o objetivo geral da presente pesquisa. Pretende-se averiguar se tal proposta legislativa viola ou não o Direito Fundamental à Educação dos filhos, cujos pais optam pela instrução domiciliar. É necessário esclarecer se a dimensão jurídica do Direito à Educação restringe-se à instrução ou inclui também o direito da criança ir à escola. Necessário também analisar a titularidade desse direito, ou seja, será investigado se a Educação é considerada ou não um direito personalíssimo do filho.O homeschoolingé a negativa dos pais à Instituição Escolar, ou seja, os genitores que escolhem a educação domiciliar assim agem porque negam a Escola enquanto Instituição. Não há a negativa da instrução técnico-formal de seus filhos, uma vez que o ensino ocorre no âmbito do lar da família. Por razões religiosas, morais, preocupados com a segurança de seus filhos estudarem em escolas com alto índice de violência ou por outros motivos os pais escolhem oferecer a instrução aos seus filhos em casa.A interpretação constitucional do Direito Fundamental à Educação deve ser extensiva, sistemática e compatível com as proposições teóricas apresentadas pelo Estatuto da Criança e do Adolescente. Oferecer a instrução técnica aos filhos em casa é uma decisão tomada pelos pais que pode ser vista como uma forma de retirar das crianças o direito de frequentar o ambiente escolar, local onde se aprende e apreende não apenas o ensino formal mas, sim, a possibilidade de buscar uma formação ética, a construção dos valores da tolerância, solidariedade, respeito ao próximo e socialidade. O Projeto de Lei 3179/12 é considerado juridicamente inconstitucional pelo fato de configurar expressa afronta ao Direito Fundamental à Educação, que é indisponível, personalíssimo e cuja titularidade pertence à criança, não aos seus pais.

Palavras-chave: Homeschooling, Constitucionalidade, Projeto de lei 3179/12

\footnotetext{
${ }^{1}$ Doutor em Direito Processual pela Pontifícia Universidade Católica - PUC, Belo Horizonte - MG (Brasil). Professor da Faculdade de Pará de Minas, Para de Minas - MG (Brasil). E-mail: fvcufu@uol.com.br
} 


\begin{abstract}
The movement of home education erupted in the United States from the 60's, influenced by progressive educators considered that led many parents choose to educate their children outside the public school system. The draft Law 3179/12, authored by Mr Diniz Lincoln Portela, proposes to add a paragraph in Article 23 of Law 9394/96 (Law Guidelines and National Base) to enable the home supply of basic education. The analysis of the constitutionality of the relevant bill is the main objective of this research. It is intended to ascertain whether such a proposal violates legislative or not the Fundamental Right to Education of children whose parents opt for home education. It is necessary to clarify the legal dimension of the right to education is limited to instruction or also includes the right of the child to go to school. Also necessary to examine the ownership of this right, ie it will be investigated whether education is considered or not a personal right of filho.O homeschoolingé the refusal of parents to the School Institution, namely the parents who choose to homeschool so act because they deny School as an institution. No negative technical-formal education of their children, since the teaching takes place within the family home. For religious, moral, concerned about the safety of their children studying in schools with high levels of violence or other reasons parents choose to offer education to their children in home.The constitutional interpretation of the Fundamental Right to Education should be extensive, systematic and compatible with the theoretical proposals presented by the Child and Adolescent. Provide technical education to the children at home is a decision taken by parents who can be seen as a way to remove the children the right to attend the school environment, where one learns and grasps not only formal education but rather the possibility to seek an ethical training, the construction of the values \&\#8203;\&\#8203; of tolerance, solidarity, respect for others and sociality. The 3179/12 Bill is considered legally unconstitutional because configure expressed outrage at the Fundamental Right to Education, which is unavailable, very personal and whose ownership belongs to the child, not the parents.
\end{abstract}

Keywords: Homeschooling, Constitutionality, Bill 3179/12 


\section{INTRODUÇÃO}

O objetivo geral da presente pesquisa é desenvolver um estudo acerca da constitucionalidade do Projeto de Lei 3179/12,que propõe a alteração do artigo 23 da Lei 9394/96 (lei de Diretrizes e Base Nacional) com a finalidade de possibilitar a implementação jurídica do homeschoolingno ordenamento brasileiro. Especificamente pretende-se investigar o fenômeno sócio-cultural do homeschooling, buscando, inicialmente, compreender sua gênese no plano internacional para, num segundo momento, analisar os seus reflexos no contexto da sociedade e do direito brasileiro.

Importante ressaltar que o objeto da presente pesquisa é a abordagem jurídica do tema homeschoolingno cenário do Direito brasileiro vigente e a constitucionalidade do Projeto de Lei 3179/12. Não se busca desenvolver um estudo do tema no âmbito do Direito Comparado, haja vista que a proposta apresentada é refletir se tal fenômeno se compatibiliza ou não com o direito pátrio e a ordem constitucional democrática vigente. O ponto central de toda reflexão cientifica consiste na análise da legitimidade jurídica dos genitores que resolvem oferecer o ensino aos seus filhos em casa, de forma a averiguar se tal decisão caracteriza ou não violação do Direito Fundamental à Educação, tendo em vista que o Estatuto da Criança e do Adolescente, ao instituir o princípio da proteção aos filhos, deixa claro que toda criança tem o direito de estar regularmente matriculada numa Instituição de Ensino.

O estudo jurídico do tema homeschooling é uma forma de analisar se o exercício do poder familiar pelos genitores das crianças os legitima ou não a oferecer a instrução em casa. No momento em que os pais optam pela educação domiciliar estariam deslegitimando o Estado no que tange ao direito que lhes cabe de oferecer instrução às crianças no ambiente escolar? $\mathrm{O}$ Homeschooling é uma prática pedagógica condizente com o Estatuto da Criança e do Adolescente? Há violação de Direitos Fundamentais no caso de criança submetida à instrução formal domiciliar imposta pelos pais? Os pais podem escolher se seus filhos têm ou não o direito de irem à escola?

As hipóteses científicas propostas nortearão a discussão do tema-problema ao longo dessa pesquisa. Para isso, analisar-se-á primeiramente o principio da proteção dos filhos, expressamente previsto no Estatuto da Criança e do Adolescente, de modo a compreender se a prática do homeschooling afronta ou não o disposto no artigo 55 da Lei 8069/90, que é categórico ao afirmar que os pais ou responsáveis têm a obrigação de matricular seus filhos ou pupilos na rede de ensino. 
O movimento da desescolarização e da educação domiciliar que surgiu a partir da década e 60 nos Estados Unidos da América decorre de severas críticas ao sistema de ensino vigente à época e propõe sua revisitação a partir da concepção de que as pessoas aprendem se comunicando e compartilhando experiências umas com as outras. $\mathrm{O}$ aluno passa gozar de uma autonomia plena e quase absoluta de conhecer o que ele deseja. Não são mais as instituições de ensino que sistematizam os parâmetros que direcionaram o processo ensino-aprendizagem. A partir dessas proposições teóricas preconizadas por Holt o Estado seria deslegitimado a definir os conteúdos científicos a serem trabalhados em cada idade e ciclo escolar. O aluno, seja adulto ou criança, é dotado de uma autonomia e maturidade pressuposta o suficiente para decidir o que quer aprender; quando quer aprender; de que forma quer aprender.

O pensador austríaco Ivan Illich $(1926,2002)$, em sua clássica obra intitulada "Sociedade sem Escolas", faz severas criticas à institucionalização da educação nas sociedades contemporâneas, que embora não tenha se vinculado diretamente ao movimento dohomeschooling, construiu muitas proposições teóricas em favor da abolição da compulsoriedade da educação. Nos dizeres de Illich (1985, p. 22) "Paradoxalmente, a convicção de que a escolarização universal é absolutamente necessária, mantém-se mais firmemente nos países em que menos pessoas serão servidas por escolas". A maioria das pessoas adquire a maior parte de seus conhecimentos fora da escola, uma vez que o aprendizado decorre de casualidades e não de uma instrução programada.

Esse é o contexto teórico em que se desenvolverá a presente pesquisa cientifica. Antes de analisarmos a constitucionalidade e a legalidade do fenômeno social do homeschoolingno Brasil, torna-se necessário compreender sua gênese, ou seja, é imprescindível averiguar preliminarmente onde surgiu o homeschooling, em qual contexto histórico, quais são as motivações que levam os genitores escolherem a educação domiciliar para seus filhos. Em seguida, compreender-se-á tal fenômeno no Brasil, onde temos a Associação Nacional de Educação Domiciliar, com um aumento significativo a cada ano do número de casos de homeschooling. Ao final, desenvolver-se-á um estudo especificamente jurídico do tema com o condão de analisar sua compatibilidade ou não com o direito brasileiro vigente sob a ótica da proteção jurídica dos direitos das crianças.

No que tange à metodologia utilizada realizar-se-á pesquisa documental e análises interpretativas do Estatuto da Criança e do Adolescente, Lei de Diretrizes e Base da Educação (Lei 9434/96), Projeto de Lei 3179/12 (de autoria do parlamentar Lincoln Portela). A pesquisa teórico-bibliográfica será desenvolvida a partir da análise, leitura e estudos de livros e textos científicos de pesquisadores que estudaram direta ou indiretamente 
o tema objeto da pesquisa. A pesquisa documental será realizada por meio de levantamento de dados quantitativos secundários, elementos esses considerados indispensáveis à construção de análise crítica, temática, interpretativa, jurídica e comparativa do objeto da presente pesquisa.

\section{A GÊNESE DO FENÔMENO SÓCIO-CULTURAL DO HOMESCHOOLING}

Os sistemas estatais de escolarização em massa é uma construção histórica decorrente da clássica concepção de que lugar de criança é na escola, uma vez que o fenômeno da escolarização obrigatória é reflexo do imperativo social e ideológico da cultura mundial (RAMIREZ; BOLI, 1987) utilizado como parâmetro pelos governos autocráticos da Prússia e Áustria, no século XVII, com o objetivo específico de construir um estado-nação unificado.

As décadas de sessenta e setenta do século vinte foram marcadas por severas críticas ao sistema educacional norte-americano, fato esse que desencadeou um crescimento vertiginoso do movimento pela home education. As obras de John Holt e Illich contribuíram significativamente para a construção de proposições teóricas utilizadas para questionar a capacidade da escola moderna desenvolver processo de ensinagem eficaz e suficientemente capaz de estimular nos seus alunos a curiosidade e o desejo pela aprendizagem.

O homeschoolingé um fenômeno social mundial que ocorre em pelo menos 63 países. Conforme dados da Home School Legal DefenseAssociantion, o homeschoolingnão é expressamente proibido por lei, destacando-se que em muitos países a legislação é omissa e contraditória, algo que compromete substancialmente o levantamento de dados confiáveis quanto ao cálculo da população mundial que adere a essa modalidade de ensino (VIEIRA, 2012, p. 13 ).

Os Estados Unidos concentram a maior população de homeschoolingdo mundo, estimada em cerca de 2,04 milhões de casos, tendo ocorrido um crescimento superior a 100\% no período de 1999 a 2010 e representa hoje 3,8\% da população escolar de todo o país. O fenômeno concentra-se nas famílias cristãs da região do sul rural americano e tem a religião e os valores morais como motivação central. A ausência de uma regulamentação legal do tema em todos os estados americanos tem colocado em pauta a discussão dos direitos parentais e da liberdade de educar seus filhos em casa. A literatura americana sobre o home educationjá nos permite traçar um perfil da seleta população praticante: são majoritariamente filhos de famílias brancas, de classe média, protestantes, com pais casados, mães de tempo 
integral ou quase, pais provedores, bem escolarizados em comparação com a média nacional. Os pais educadores normalmente são multidimensionais e justificam suas escolhas por motivações ideológicas (os pais desejam que seus filhos tenham uma visão ideológica bem particular sobre o mundo); motivações pedagógicas (os pais buscam preparar educacionalmente as crianças de modo a incutir visões particulares) e motivações ambientais (os pais visam proteger seus filhos de visões negativas encontradas nas escolas, tais como violência, drogas). Ou seja, dentre os principais motivos das famílias americanas adeptas do homeschoolingdestacamos os seguintes: a- preocupação com o ambiente das escolas regulares, algo que inclui segurança, drogas ou pressão do grupo; b- oferecer instrução religiosa ou moral aos seus filhos; c- insatisfação com a instrução nas escolas regulares; d- necessidades especiais dos filhos; e- outras razões, tais como, a distância, finanças e a necessidade de um ensino individualizado (VIEIRA, 2012) ${ }^{1}$.

No Estado Australiano de Nova Gales do Sul estima-se que a expansão de estudantes domiciliares, entre 2003 e 2009, tenha sido de cerca de 60\%; na Rússia estima-se que entre 2008 a 2012 ocorreu um crescimento de $900 \%$ dos casos de crianças instruídas em casa. A maior população de homeschoolingdo mundo encontra-se concentrada nos Estados Unidos, França, Canadá, Austrália, Reino Unido, África do Sul, Rússia e Austrália, ressaltando-se que o predomínio do respectivo fenômeno social ocorre em países anglo-saxões devido à tradição jusnaturalista na história britânica, cujas instituições jurídicas preconizam pelo parental rights, ou seja, o direito que os pais tem de escolher, sem a intervenção estatal, qual tipo de educação oferecerão aos seus filhos (VIEIRA, 2012) ${ }^{2}$.

Há registros de países em que o homeschoolingé proibido, como é o caso da Alemanha, onde temos dezenas de relatos de pais que foram multados, presos e perderam a custódia de seus filhos. Jürgen e Rosemary Dudek, casal alemão residente em Archfield, enfrenta processo judicial que se arrasta por mais de cinco anos, já tendo sido condenado em 2008 a 90 dias de prisão.

Outro caso emblemático ocorreu na Suécia, que envolveu o garoto sueco Domenic Johansson, que em 26 de junho de 2009, quando tinha 07 anos, foi tomado de sua família e, desde então, vive com uma família adotiva e o governo só permite a visita dos pais uma vez a cada cinco semanas e contatos de quinze minutos por telefone a cada duas semanas. Em razão disso, inúmeras famílias alemãs e suecas se refugiam em outros países com

${ }^{1}$ Disponível em http://bdm.unb.br/bitstream/10483/3946/1/2012_AndredeHolandaPadilhaVieira.pdf. Acesso em 18 jan. 2015 2 Disponível em http://bdm.unb.br/bitstream/10483/3946/1/2012_AndredeHolandaPadilhaVieira.pdf. Acesso em 18 jan. 2015. 
o objetivo de instruírem seus filhos em casa. Em setembro de 2010, quatro famílias de Botswana pertencentes à Igreja Adventista do Sétimo Dia foram presas por desobedecerem a ordem judicial de matricularem seus filhos na escola (VIEIRA, 2012) ${ }^{3}$.

No Brasil, a ausência de dados oficiais sobre a quantidade de famílias que educam em casa, compromete a mensuração do respectivo fenômeno social. O movimento brasileiro a favor da educação domiciliar ainda é bem incipiente, não se conhecendo, além da ANED (Associação Nacional de Educação Domiciliar), qualquer outra instituição ou associação formal dedicada à defesa do homeschooling. "Segundo a Aned (Associação Nacional de Educação Domiciliar), há mil famílias associadas no grupo. Mas Ricardo Iene, cofundador do órgão, calcula que, pela quantidade de e-mails que recebe, sejam mais de 2 mil famílias educando seus filhos em casa no Brasil” (BRASIL) 4 .A produção acadêmica brasileira sobre o tema ainda é acanhada, mas os críticos dessa modalidade de ensino afirmam que educar em casa é "humanizar um sujeito numa espécie de bolha protetora calcada em preconceitos" (VIANA, 2011, p. 7) e que "a família não dá conta das inúmeras formas de vivencias de que todo o cidadão participa e há de participar” (CURY, 2006, p. 670). O monopólio estatal da compulsoriedade da educação escolar é uma questão que precisa ser inicialmente analisada com a finalidade de compreender as razões que levaram estudiosos apresentarem proposições teóricas com o condão de sistematizar a prática do homeschoolingno mundo para, num segundo momento, estudar tal fenômeno no âmbito do Brasil.

O Estado é o detentor exclusivo da legitimidade jurídica de instruir crianças nas suas instituições escolares ou tal legitimidade poderia ser compartilhada com os genitores das crianças, de modo a viabilizar o reconhecimento jurídico da prática do homeschooling?

A educação escolar entendida como uma responsabilidade do poder estatal teve sua origem durante o movimento da Reforma Protestante no século XVI, quando Martinho Lutero, buscando defender o acesso igualitário a uma educação para todos, teorizou a responsabilidade do Estado pela oferta, manutenção, supervisão e controle de freqüência dos alunos no que atine ao monopólio da instrução técnico-científico-formal de todos indivíduos indistintamente (BARBOSA, 2011).

\footnotetext{
3 Disponível em http://bdm.unb.br/bitstream/10483/3946/1/2012_AndredeHolandaPadilhaVieira.pdf. Acesso em 18 jan. 2015.

${ }^{4}$ Disponível em http://www.bbc.co.uk/portuguese/noticias/2013/11/131104 educacao domiciliar abre vale md b. Acesso em 11 jan. 2015.
} 
Boudens (2005, p. 8) afirma que a compulsoriedade do ensino fundamental é produto tanto da Revolução Francesa, calcada "no ideal de promover a igualdade de oportunidades de ascensão social e de acesso ao trabalho produtivo", quanto da Revolução Industrial, que sedimentou a "necessidade de impor aos indivíduos uma conduta social padronizada". Para Carlos Jamil Cury (2002, p. 250) a educação primária, gratuita e obrigatória no século XIX justifica-se "no sentido de a sociedade produzir pessoas com mentes maduras, minimamente iluminadas, capazes de constituir eleitorado esclarecido e trabalhadores qualificados".

O século XX caracteriza-se pelo reconhecimento da educação primária, compulsória, gratuita e fornecida pelo Estado. Os Tratados Internacionais de Direitos Humanos passam a dar tratamento jurídico às crianças como sujeito de direito, especificamente a Convenção Sobre os Direitos da Criança, que foi fundamental para a sistematização legal do tema em diversos países ao redor do mundo. No momento em que o Estado assume a obrigação de oferecer ensino obrigatório e gratuito aos seus cidadãos busca proporcionar condições para que todos os indivíduos indistintamente possam exercer, de forma efetiva, sua cidadania.

A escola passa a ser vista como o lócusda instrução técnico-formal utilizada para habilitar seus indivíduos a exercer mais conscientemente seus direitos e compreender o mundo de uma forma mais racional. Em razão de a escola ser um espaço de acolhimento de pessoas das mais diversas origens, raça, idade e classe social o seu papel passa a ser contestado diante de suas contradições ou impossibilidade de realização de suas finalidades propostas (SACRISTÁN, 2001, p. 71).

A gênese do homeschoolingpode ser encontrada a partir de críticas feita à compulsoriedade e ao monopólio estatal da educação.

A educação obrigatória legitima os adultos no exercício do direito de moldar as crianças de acordo com os seus valores e percepções do mundo. Retira-se da criança o direito de escolher o tipo de educação ao qual se submeterá; tolhe-se o direito de a criança escolher a instituição de ensino onde estudará e também não se permite conceder liberdade da criança estar e permanecer fora do sistema educacional. Mesmo que a criança não goste da escola, na Inglaterra, por exemplo, os pais têm o direito de mantê-las na escola na idade dos 5 até os 16 anos. Isso é considerado para Colbeck uma espécie de abuso educacional, uma vez que a criança tem a liberdade de escolher se quer estudar, se prefere estudar numa instituição de ensino especifica ou mesmo em casa (COLBECK, 2001, p. 275). 
Para Filipe Celeti, a instrução formal não pode ser obrigatória e nem regulamentada pelo Estado, uma vez que entende necessária e coerente a separação entre Estado e Educação, de modo que a formação cientifica decorra da manifestação voluntária e livre de cada indivíduo (2011, p. 85).

Para Celeti, o Estado não goza da legitimidade de se utilizar de meios coercitivos para que as pessoas sejam instruídas, educadas e escolarizadas (2011, p. 48). Posiciona-se na defesa da liberdade individual, por entender que uma lei não pode obrigar todas as crianças a frequentar a escola. O ensino em casa passa a ser visto, nesse contexto, como uma das mais possíveis alternativas à educação obrigatória decorrente da compulsoriedade do monopólio estatal.

Os defensores do ensino em casa se posicionam contrariamente ao monopólio e ao direcionismo estatal, assim como criticam a educação escolar compulsória, uma vez que se pautam no pensamento liberal do não intervencionismo estatal e prevalência das liberdades individuais.

A padronização do modelo de ensino pelas instituições é vista como uma forma de retirar a liberdade das famílias escolherem um sistema de ensino compatível com sua formação moral, suas crenças e valores. Dessa forma, o Estado não teria a legitimidade jurídica de instituir um sistema de educação único e padronizado para todos, uma vez que a partir do pensamento liberal, cada pessoa teria o direito de escolher o modelo e o sistema de ensino que adotaria para si e para seus filhos.

No entendimento de Auberon Herbert (1978, p. 30), da mesma forma que o Estado não tem legitimidade para direcionar qual será a religião adotada por cada cidadão, também não deveria ter o direito de estabelecer o tipo de educação a ser dada uniformemente para todos.

$\mathrm{O}$ fato de as pessoas formarem uma nação e ter aqueles que as governam não significa lhes atribuir ilimitadamente o direito de interferir na educação e na religião. Se a liberdade é a condição que regula a vida humana a compulsoriedade da educação escolar representaria um direcionismo estatal infundado.

John Holt e Ivan Illich são teóricos que se tornaram referência para a idealização e a prática do ensino em casa através da divulgação de seus trabalhos de pesquisa nos Estados Unidos da América.

Os escritos de Illich ganharam mais evidência na década de 70, quando tivemos a publicação de seu livro intitulado "Sociedade sem Escolas", onde faz severas críticas às 
instituições escolares por entender que elas foram criadas para atender as necessidades da sociedade e, em decorrência disso, tais instituições aprisionavam seus alunos e limitavam sua visão crítica do mundo. Para o autor, as instituições, além de impor uma concepção da realidade do mundo aos seus alunos reproduziam o pensamento da classe dominante, construindo a ideologia de que o progresso da sociedade apenas ocorreria mediante a existência e a expansão das próprias instituições.

As críticas feitas à escolarização e o advento do movimento da desescolarização decorre do fato de que tais instituições foram criadas especificamente para reproduzirem o pensamento de uma sociedade regida e conduzida por uma classe dominante.

A escola é vista pelo autor como o lócusem que a classe dominada adere, de forma incontestável, à forma de pensar da classe dominante. Nos dizeres de Illich, citado por Luciane Muniz Ribeiro Barbosa, "a educação escolar passa a ser, então, um mecanismo de alienação dos sujeitos em formação, que tomam como verdadeiros e válidos os valores instituídos pela classe dominante para preservar seus interesses, em detrimento dos interesses comuns da sociedade (2013, p. 94).

As criticas de Illich ao monopólio estatal da educação formal justificam- se na ideológica concepção de que somente através da educação formal obrigatória é que se pode obter o saber legitimado e reconhecido na sociedade. Pretendeu o autor revisitar o entendimento de que todo saber ensinado fora da escola não tem valor, uma vez que vê a escolarização obrigatória como um limitador do direito de liberdade de escolha em razão do direcionismo estatal.

Os escritos de John Holt exerceram influência direta no movimento dos defensores do homeschooling. Holt foi um educador norte-americano (1923-1985) e considerado um dos ferrenhos defensores do homeschoolingem seu pioneiro estudo sobre a teoria dos direitos da juventude. Ao longo de sua produção cientifica sustentou que a escolarização compulsória corrói a natural curiosidade epistemológica das crianças, uma vez que limita sua liberdade de escolha. Nesse sentido, Holt afirma que as crianças "aprendem onde quer que estejam, não somente em locais especiais de ensino" (1989, p. 162).

Pode-se considerar Holt como o precursor do homeschooling. Tanto Illich quanto Holt defendiam a eliminação da compulsoriedade na educação estatal como forma de viabilizar a construção de uma sociedade mais livre e humana. Um dos fundamentos que justificam o homeschoolingé a legitimidade que as crianças têm de participarem de forma ativa da construção do processo ensino- aprendizagem. 
Na década de 80 nos Estados Unidos da América temos o fortalecimento do movimento em prol do ensino em casa a partir de premissas e justificativas religiosas. Essa década nos Estados Unidos foi marcada por severas criticas de Holt e Moore à escola pública e, em virtude disso, foram construindo gradativamente uma visão de que o homeschooling é uma alternativa a essa falência do ensino público. André de Holanda Padilha Vieira (2015) afirma que o movimento em prol do homeschooling pauta-se no direito divino de os pais educarem seus filhos.

Importante ressaltar que temos uma notável prevalência das populações de homeschoolers nos países anglo-saxões, algo explicável em razão da prevalência dos parental rights e também pelo fato desse fenômeno ser mais comum nos países mais bem situados na escala de desenvolvimento humano e econômico. É por isso que temos um número mais baixo de famílias praticantes do homeschooolingnas América Central e do Sul, bem como no continente africano.

\section{A EXPOSIÇÃO DE MOTIVOS DO PROJETO DE LEI 3179/12 E UMA ANÁLISE PRELIMINAR DE SUA CONSTITUCIONALIDADE E LEGALIDADE}

O Projeto de Lei 3.179/2012 é de autoria do Deputado Federal Lincoln Diniz Portela, do Partido Republicano, Estado de Minas Gerais. Trata-se de uma proposta legislativa que visa acrescentar parágrafo ao artigo 23 da Lei 9.394/97, Lei de Diretrizes e Bases da Educação Nacional, com o condão de dispor sobre a possibilidade de oferta domiciliar de educação básica. Apresentado formalmente em 08 de fevereiro de 2012, o respectivo projeto propõe a seguinte redação ao $§ 3^{\circ}$, do artigo 23 da Lei 9394/97:

$\S 3^{\circ}$ É facultado aos sistemas de ensino admitir a educação básica domiciliar, sob a responsabilidade dos pais ou tutores responsáveis pelos estudantes, observadas a articulação, supervisão e avaliação periódica da aprendizagem pelos órgãos próprios desses sistemas, nos termos das diretrizes gerais estabelecidas pela União e das respectivas normas locais.

Argumenta o autor da proposta que na realidade brasileira a oferta da educação básica se faz tradicionalmente no ambiente escolar. Porém, verifica- se não haver qualquer impedimento para que a mesma formação seja oferecida no ambiente domiciliar, desde que assegurada sua qualidade e o devido acompanhamento pelo Poder Público certificador. Trata- 
se de uma forma de reconhecer o direito de opção das famílias com relação ao direito da responsabilidade educacional para com seus filhos.

Como relator do Projeto de Lei em tela foi indicado o Deputado Federal do Estado de Alagoas, Maurício Quintella Lessa, do Partido Republicano. Em 07 de novembro de 2012 manifestou-se formalmente sobre a presente proposta legislativa, não tendo apresentado qualquer emenda. Em seu parecer, inicialmente destacou que a Constituição Federal de 1988 estabelece que a educação é um dever do Estado e da família, ressaltando-se a obrigatoriedade da educação básica dos 04 aos 17 anos de idade, conforme preconiza os artigos 205, 206 e 208 do texto constitucional vigente.

Destacou o parlamentar que o movimento em prol do ensino domiciliar é crescente nos últimos dez anos no Brasil. Na realidade brasileira a oferta do ensino básico se faz tradicionalmente pela via da educação escolar. Sustenta não haver impedimento para que a mesma formação, se assegurada a qualidade e o devido acompanhamento pelo Poder Público certificador, seja oferecida no ambiente domiciliar. Ao final de seu parecer, manifestou-se favoravelmente à respectiva proposta, ressaltando-se que caberá sempre o controle por parte do Poder Público com relação à qualidade e efetividade do ensino domiciliar ministrado.

Em 12 de junho de 2013 a Comissão de Educação designou como relatora do projeto a professora e Deputada Federal Dorinha Seabra Rezende (DEM- TO). Buscando-se amadurecer o debate da respectiva temática, em 12 de novembro de 2014 foi realizada Audiência Pública com a participação dos seguintes profissionais: Professora. Clélia Mara dos Santos, da Coordenação Geral de Redes Públicas da Secretaria de Educação Básica do Ministério da Educação - MEC; do Professor Rossieli Soares da Silva, Secretário de Estado da Educação e da Qualidade de Ensino do Estado do Amazonas, representando o Conselho Nacional de Secretários de Educação - CONSED; Professor Luiz Carlos Faria da Silva, do Departamento de Fundamentos da Educação da Universidade Estadual de Maringá; e do ProfessorÉdison Prado de Andrade, analista da Secretaria Nacional de Assistência Social do Ministério do Desenvolvimento Social.

A Comissão de Educação foi a primeira a se manifestar sobre o mérito da temática abordada no projeto de lei. A educação domiciliar é um tema recorrente no cenário das políticas públicas educacionais e também nos espaços voltados à deliberações legislativas. Em 2001, o Projeto 6001; em 2002, o Projeto 6.484; em 2008, o Projeto 3.518 e ainda em 2008 o Projeto 4.122 são exemplos de propostas legislativas voltadas a institucionalizar 
o ensino básico domiciliar no Brasil. Ressalta-se que todos os projetos, ora mencionados, foram rejeitados pela Comissão de Educação e Cultura.

O primeiro argumento utilizado para contestar a constitucionalidade do projeto de lei foi a violação do $\S 3^{\circ}$, do artigo 208 da Constituição brasileira de 1988, que estabelece que “compete ao Poder Público recensear os educandos no ensino fundamental, fazer-lhes a chamada e zelar, junto aos pais ou responsáveis, pela freqüência à escola”.

Outro argumento para questionar a legalidade dos projetos de lei supramencionados foi que os estudantes em educação domiciliar estariam privados dos processos pedagógicos desenvolvidos no espaço escolar, que promovem a socialização e a formação para a cidadania, além de se tratar de alternativa elitista, pois sua prática seria possível apenas para famílias de mais alto capital cultural.

Estabelece o artigo 208, inciso I da Constituição brasileira de 1988 que a educação básica, dos quatro aos dezessete anos de idade, é obrigatória, cabendo ao Estado oferecê-la e à família assegurar que a criança e o adolescente a ela tenha acesso efetivo e exitoso.

É muito importante esclarecer que o Projeto de Lei 3.179/2012, ao apresentar proposições quanto à educação domiciliar, propõe o compartilhamento das responsabilidades da família e das instituições escolares oficiais, ainda que em grau distinto do tradicionalmente praticado no sistema educacional brasileiro. É importante, ainda, que o órgão competente do sistema de ensino mantenha registro da opção dos pais ou responsáveis, autorize a prática, faça o acompanhamento qualificado dos estudantes nessa situação e promova inspeções periódicas.

Deverão os estudantes se submeterem a avaliações periódicas em escolas oficiais.

Considerando-se as críticas apresentadas, a Comissão de Educação apresentou ao Projeto de Lei 3.179/2012: as seguintes alterações:

Art.23, § $3^{\circ}$ Os sistemas de ensino admitirão a educação básica domiciliar, sob a responsabilidade dos pais ou tutores responsáveis pelos estudantes, observadas a articulação, supervisão e avaliação periódica da aprendizagem pelos órgãos próprios desses sistemas, nos termos das diretrizes gerais estabelecidas pela União e das respectivas normas locais, que contemplarão especialmente: I - autorização pelo órgão competente do sistema de ensino; II - a avaliação prévia, pelo órgão competente do sistema de ensino, da qualificação dos pais ou responsáveis para conduzir o processo de ensino e aprendizagem do estudante; III - obrigatoriedade de matrícula do estudante em escola pública ou privada em regular funcionamento; IV - manutenção de registro oficial das famílias optantes pela educação domiciliar; V - cumprimento de currículo mínimo e avaliação da aprendizagem, nos termos e na periodicidade 2 estabelecidos no projeto pedagógico da escola em que o estudante estiver matriculado; VI - participação do estudante nos exames do sistema nacional e local de avaliação da educação básica; VII - previsão de inspeção educacional, pelo órgão competente do sistema de ensino, no ambiente em que o estudante estiver recebendo a educação domiciliar. 
Art.32.. $\S 4^{\circ} \mathrm{O}$ ensino fundamental será presencial, sendo o ensino a distância utilizado como complementação da aprendizagem ou em situações emergenciais e observado o disposto no $\S 3^{\circ}$ do art. 23 desta lei." (NR). Art. $2^{\circ}$ Esta lei entra em vigor na data de sua publicação.

Nessa nova proposta apresentada pela Comissão de Educação a educação básica domiciliar é de responsabilidade dos pais ou tutores do estudante, que deverá se submeter à fiscalização e avaliação periódica da aprendizagem pelos próprios órgãos estatais que integram o sistema de ensino. Foi proposta a necessidade de uma avaliação prévia, pelo órgão competente do sistema de ensino, da qualificação dos pais ou responsáveis para conduzir o processo de ensino e aprendizagem do estudante. As famílias optantes pela educação domiciliar deverão ser mantidas num registro oficial (cadastro nacional), garantindo-se o cumprimento do currículo mínimo, a avaliação da aprendizagem periodicamente, participação do estudante no sistema nacional e local de avaliação da educação básica O órgão competente do sistema de ensino tem legitimidade para exercer a inspeção educacional.

\section{PRINCÍPIO DA PROTEÇÃO DOS FILHOS}

A doutrina da Proteção Integral do Menor foi inicialmente sistematizada no ano de 1959, através da Declaração dos Direitos da Criança oriunda do $8^{\circ}$ Congresso da Associação Internacional de Juízes de Menores, ocorrida em Genebra. Tal Declaração foi adotada pela Assembléia das Nações Unidas de 20 de novembro de 1959 e ratificada pelo Brasil, através do artigo 84, inciso XXI da Constituição brasileira de 1988, tendo em vista o disposto nos artigos $1^{\circ}$ da Lei $n^{\circ} 91$, de 28 de agosto de 1935 e $1^{\circ}$ do Decreto $\mathrm{n}^{\circ} 50.517$, de 2 de maio de 1961. Ou seja, a Convenção Internacional sobre o Direito das Crianças foi aprovada pela Assembléia Geral das Nações Unidas em 20 de novembro de 1989 e pelo Congresso Nacional brasileiro em 14 de setembro de 1990, através do Decreto Legislativo de ${ }^{\circ} 28$ (a ratificação ocorreu com a publicação do Decreto n n $^{\circ} 9.710$ em 21 de novembro de 1990, através do qual o então Presidente da República promulgou a Convenção).

A Declaração Internacional dos Direitos da Criança preconiza a ampla e integral proteção das crianças, ressaltando que são credoras de direitos independentemente de qualquer discriminação ou distinção decorrente da raça, cor, sexo, língua, religião, opinião política ou qualquer outra condição, quer sua ou de sua família. O Estado, a Sociedade e a Família garantirão a proteção social das crianças, de modo a lhes proporcionar o desenvolvimento 
físico, mental, moral, espiritual e social, de forma sadia, normal e em condições de liberdade e dignidade. Desde o nascimento a criança passa a ter direito a um nome e a uma nacionalidade, podendo gozar dos benefícios da previdência social, com direito a crescer e criar-se com saúde e com acesso à alimentação, recreação e assistência médica adequadas. Às crianças portadoras de necessidades especiais serão proporcionados o tratamento, a educação e os cuidados especiais exigidos pela sua condição peculiar. Às crianças será assegurado o direito a um ambiente familiar de afeto, de segurança moral e material, cabendo ao Estado e à sociedade a obrigação de proporcionar cuidados especiais às crianças sem família e àquelas que carecem de meios adequados de subsistência (BRASIL, Biblioteca Virtual de Direitos Humanos,

2015).

Ainda segundo aDeclaração Internacional supramencionada a criança terá direito a receber educação, que será gratuita e compulsória pelo menos no grau primário. A educação deverá ser capaz de promover sua cultura geral e capacitá-la, em condições de iguais oportunidades, desenvolver suas aptidões, sua capacidade de emitir juízos e senso de responsabilidade moral e social, e a tornar-se um membro útil da sociedade. Os melhores interesses da criança serão a diretriz a nortear os responsáveis pela sua educação e orientação. A sociedade, família e autoridades públicas deverão se empenhar em promover às crianças o gozo do direito de brincar e divertir-se, que é titular do direito de preferência a receber proteção, socorro e atendimento médico-hospitalar. (BRASIL, Biblioteca Virtual de Direitos Humanos, 2015).

A dimensão do principio da proteção integral garante às crianças a proteção contra quaisquer formas de negligência, crueldade e exploração, não sendo permitido antes da idade mínima conveniente qualquer ocupação ou emprego que lhe prejudique a saúde, a educação ou que interfira em seu desenvolvimento físico, mental ou moral.(BRASIL, Biblioteca Virtual de Direitos Humanos, 2015).

Em 1988 a Constituição brasileira, no seu artigo 227, caput, sistematizou as premissas decorrentes da Declaração Internacional dos Direitos da Criança ao prever expressamente o fundamento do principio da proteção integral no direito interno:

É dever da família, da sociedade e do Estado assegurar à criança, ao adolescente e ao jovem, com absoluta prioridade, o direito à vida, à saúde, à alimentação, à educação, ao lazer, à profissionalização, à cultura, à dignidade, ao respeito, à liberdade e à convivência familiar e comunitária, além de colocá-los a salvo de toda forma de negligência, discriminação, exploração, violência, crueldade e opressão (BRASIL, Artigo 227 da Constituição Federal de 88, 2015). 
A adoção no ordenamento jurídico brasileiro da doutrina da proteção integral aconteceu de forma coerente com os documentos e protocolos internacionais aprovados com amplo consenso e debate pelas comunidades, organizações e nações internacionais.

A Constituição brasileira de 1988 estabelece proposições normativas que regulam a interpretação e a validade de todo o ordenamento jurídico brasileiro. Nesse primeiro momento pretende-se demonstrar os fundamentos constitucionais que justificam a proteção integral das crianças no Brasil. O princípio da dignidade da pessoa humana ${ }^{5}$ encontra-se expressamente previsto no artigo $1^{\circ}$ da Constituição brasileira de 1988 e é elevado a Fundamento da República Federativa do Brasil. Trata-se de principio que garante a ampla e integral proteção jurídica das crianças, de modo a oportunizar-lhes o exercício efetivo dos Direitos Fundamentais. No texto da Constituição brasileira de 1988 foi inserido um sistema especial de proteção para as crianças e adolescentes, reconhecidos na condição especial de seres humanos ainda em desenvolvimento físico, psíquico e emocional. Importante esclarecer que a doutrina da proteção integral não está restrita ao artigo 227 e seus parágrafos, uma vez que permeia os artigos 205, 206, 208, 201, 212, 213, 214 e 228, manifestando-se também de forma subsidiária nos artigos 226, caput e parágrafos $3^{\circ}, 4^{\circ}, 5^{\circ}$ e $8^{\circ}$; artigo 229 , primeira parte; incisos XXXIII e XXX do artigo $7^{\circ}$, todos da Constituição brasileira de 1988. Tais previsões legislativas explicitam formas de assegurar, tanto no plano de políticas sociais públicas, quanto no plano da tutela jurisdicional os Direitos Fundamentais de Crianças e Adolescentes.

A vida e a saúde são Direitos Fundamentais decorrentes diretamente do principio da dignidade da pessoa humana. O Direito à Proteção Especial pode ser visualizado na garantia de exercício de direitos previdenciários e trabalhistas; garantia de acesso do trabalhador adolescente à escola; na idade mínima de 14 anos para trabalhar na condição de aprendiz, sendo vedada a realização de atividades insalubres e periculosas; garantia de exercício dos princípios do contraditório, ampla defesa, devido processo legal e duração razoável do processo em caso de prática de ato infracional; obediência aos princípios da brevidade, excepcionalidade e respeito à condição peculiar de pessoa em desenvolvimento quando da

\footnotetext{
5 Penso, outrossim, que a dignidade da pessoa humana é o ponto de esteio do Estado Democrático brasileiro - o fundamento básico dele, o ápice da pirâmide valorativa do ordenamento jurídico instituído pela CF de 1988 - eis que, mesmo quando cotejada aos demais fundamentos referidos de maneira expressa no artigo $1^{\mathrm{o}}$ da Carta Magna, ela tem posição de centralidade, porque atrai o conteúdo valorativo dos outros quatro. Com efeito, na essência de tudo está aquela idéia já antiga e que foi o gatilho da evolução histórica, do aprofundamento, da noção de Estado de Direito de que o homem só pode ser livre quando se edifica sobre um conjunto de homens livres, titulares de direitos fundamentais que assegurem sua dignidade humana (MACHADO, 2003, p. 97-98).
} 
aplicação de qualquer medida privativa da liberdade; estimulo do Poder Público ao acolhimento de crianças ou adolescentes órfãos ou abandonados; programas de prevenção e atendimento especializado à criança e ao adolescente dependente de entorpecentes e drogas afins.

Crianças e Adolescentes são ampla e integralmente protegidos em seus direitos e, por isso, a Constituição brasileira de 1988 estabelece que a lei punirá severamente o abuso, a violência e a exploração sexual da criança e do adolescente. A adoção obrigatoriamente deverá ser assistida pelo Poder Público, na forma da lei, que estabelecerá casos e condições de sua efetivação por parte de estrangeiros, garantindo-se a isonomia entre os filhos e vedandose quaisquer designações discriminatórias relativas ao Direito à Filiação.

A convivência familiar é um outro direito decorrente do princípio da proteção integral, cabendo ao Estado criar mecanismos para coibir a violência no âmbito de suas relações. Os pais têm o dever de assistir, criar e educar os filhos menores, assim como os filhos maiores têm o dever de ajudar e amparar os pais na velhice, carência ou enfermidade.

O artigo 205 da Constituição brasileira de 1988 estabelece expressamente que a educação é um direito de todos e dever do Estado e da família, e será promovida e incentivada com a colaboração da sociedade. O objetivo da educação, nos termos constitucionais, é garantir o pleno desenvolvimento da pessoa humana, seu preparo para o exercício da cidadania e sua qualificação para o trabalho.

O ensino no Brasil devera ser ministrado com fundamento nos princípios da igualdade de condições para o acesso e a permanência na escola; liberdade de aprender, ensinar, pesquisar e divulgar o pensamento, a arte e o saber; no pluralismo de idéias e concepções pedagógicas; gratuidade do ensino público em estabelecimentos oficiais; gestão democrática do ensino púbico, na forma da lei. Nos termos dispostos no artigo 208 e seguintes da Constituição Federal de 1988, o ensino fundamental é obrigatório e gratuito, inclusive para os que a ele não tiveram acesso na idade própria; garante-se o atendimento educacional especializado aos portadores de deficiência, preferencialmente na rede regular de ensino; atendimento em creche e pré-escola às crianças de zero a seis anos de idade; oferta de ensino noturno regular e adequado às condições do educando. O Estado tem a obrigatoriedade de implementar a Educação no Brasil, por meio de criação e execução de políticas publicas educacionais voltadas à erradicação do analfabetismo, universalização do atendimento escolar, melhoria da qualidade do ensino, formação para o trabalho, promoção humanística, cientifica e tecnológica do País. 
A doutrina da Proteção Integral passou a integrar o ordenamento jurídico brasileiro com o advento da Constituição brasileira de 1988. A partir daí passamos a conviver com a necessidade de respeitar os direitos das crianças e adolescentes, ressaltando-se que são pessoas em desenvolvimento, sujeitos de direito titulares de Direitos Fundamentais de natureza personalíssima e indisponível. O principio da prioridade absoluta tem desdobramentos e aplicabilidade em todo Direito brasileiro, tendo em vista que crianças, adolescentes e jovens têm prioridade absoluta em seus cuidados. $\mathrm{O}$ principio do melhor interesse deve ser traduzido no sentido de interpretar o sistema jurídico vigente levando-se sempre em consideração o que é melhor para o menor. O principio da cooperação é um desdobramento jurídico da doutrina da proteção integral, haja vista que estabelece que decorre de todos - Estado, família e sociedade - o dever de proteção contra a violação dos direitos da criança e do adolescente, prevenindo e reprimindo qualquer tipo de ameaça aos direitos do menor.

\section{ARTIGOS 55 E 129 DO ESTATUTO DA CRIANÇA E DO ADOLESCENTE E A SUA VIOLAÇÃO EM FACE DA PRÁTICA DO HOMESCHOOLING}

O Estatuto da Criança e do Adolescente é um microssistema jurídico (Lei 8.069/90) criado com a finalidade de implementar no plano infraconstitucional a doutrina da proteção integral. Veio para mudar conceitos e valores, transformar mentes e visões até então distorcidas quanto à questão atinente aos menores no Brasil. Trata-se de uma legislação que pormenoriza os direitos das crianças e adolescentes, regulamenta o artigo 227 da Constituição de 1988 e deve ser interpretada de forma sistemática, extensiva, contextualizada e sempre voltada à proteção dos Direitos Fundamentais.

A vida, saúde, alimentação, educação, esporte, lazer, profisssionalização, cultura, dignidade, respeito, liberdade, convivência familiar e comunitária são alguns dos direitos assegurados às crianças e adolescentes na sociedade brasileira contemporânea.

Durante muito tempo, ao longo da história, os menores foram excluídos da sociedade, sendo considerados um segmento totalmente marginalizado. Felizmente o Estatuto da Criança e do Adolescente se transformou em importante e significativa ferramenta de mudança desse quadro, colocando a Criança e o Adolescente em posição de evidência e com ampla proteção jurídica, conferindo-lhes inúmeros direitos até então inexistentes. 
Conforme alhures mencionado, a proteção jurídico-legal da Criança e do Adolescente tornou-se uma prioridade e preocupação para os povos em geral, representando o Estatuto da Criança e do Adolescente uma importante mudança de filosofia com relação ao menor.

A aplicabilidade efetiva da doutrina da proteção integral exige uma transformação no pensamento social, uma vez que crianças e adolescentes deixam de ser vistos como objeto e passam a ser protegidos juridicamente como pessoas em desenvolvimento, carentes de atenção e cuidados especiais.

A Lei 8.069/90 é regida por uma série de princípios genéricos que materializam postulados essenciais para a implementação de políticas públicas de proteção da criança e do adolescente.

Especificamente no que atine ao estudo do objeto da presente pesquisa é imprescindível o estudo do artigo 55, do Estatuto da Criança e do Adolescente, cujo teor é o seguinte: "Os pais ou responsável têm a obrigação de matricular seus filhos ou pupilos na rede regular de ensino".

No mesmo sentido é importante destacar o conteúdo do artigo 129, inciso V do Estatuto da Criança e do Adolescente: "São medidas aplicáveis aos pais e responsável: Vobrigação de matricular o filho ou pupilo e acompanhar sua freqüência e aproveitamento escolar".

O conteúdo dos dispositivos acima mencionados deixa claro a implementação legal da doutrina da proteção integral no plano infraconstitucional do ordenamento jurídico brasileiro. O Estatuto da Criança e do Adolescente, através desses dois dispositivos legais, delimitou claramente as obrigações dos pais quanto a suas responsabilidades referentes à educação dos filhos.

$\mathrm{Na}$ interpretação jurídica dos respectivos dispositivos legais deve-se levar em conta os fins sociais a que eles de destinam, os direitos individuais e coletivos em questão e, especialmente, a peculiar condição da pessoa humana em desenvolvimento. $\mathrm{O}$ disposto no artigo $6^{\circ}$ do Estatuto da Criança e do Adolescente traz o conteúdo chave, do ponto de vista teleológico, para a leitura e a interpretação desse microssistema jurídico.

A proteção dos interesses do menor deverá se sobrepor a qualquer outro bem ou interesse juridicamente tutelado, destacando-se a destinação social da legislação e o respeito à condição peculiar da criança e do adolescente. 
Interessante ressaltar que a intenção do legislador, com os referidos dispositivos legais, foi proteger integralmente os direitos dos menores em idade escolar, pessoas humanas em fase de imaturidade biopsicossocial.

A matrícula regular em rede de ensino constitui Direito Fundamental da Criança e do Adolescente. Trata-se de direito personalíssimo, indisponível, irrenunciável, cujos pais não podem limitar, suprimir ou violar o seu exercício pelos filhos ou pupilos. A universalidade, historicidade, indivisibilidade, imprescritibilidade, essencialidade, inalienabilidade, irrenunciabilidade, vedação de retrocesso são algumas características ínsitas dos Direitos Fundamentais no Estado Democrático de Direito, como forma de garantir a proteção jurídica da dignidade da pessoa humana (DIÓGENES JÚNIOR, 2015).

Além de matricular regularmente seus filhos os pais têm a obrigação de acompanhar sua freqüência e aproveitamento escolar. Tal obrigação decorre do dever de cuidado, educação, zelo, assistência material, moral e educacional que os pais assumem em relação aos seus filhos. O artigo 1566 do Código Civil brasileiro vigente estabelece que são deveres de ambos os cônjuges garantir o sustento, guarda e educação de seus filhos.

Os pais que negligenciam quanto à formação educacional de seus filhos respondem juridicamente em razão da comprovada prática de condutas ilícitas comissivas ou omissivas.

Na esfera cível, os pais que não realizam o acompanhamento escolar de seus filhos, não os matriculam em rede de ensino, deixam de assumir efetivamente a obrigação pela sua formação poderá perder ou ter suspenso o poder familiar, além de responder por eventuais perdas e danos. A desídia dos pais deve ser vista e ponderada como negligência inescusável, absoluto descaso para o qual inexiste qualquer justificativa.

No ano de 2011 o Tribunal de Justiça de Santa Catarina condenou o pai a pagar Indenização de $\mathrm{R} \$ 40.000,00$, a título de Danos Morais, decorrente do abandono intelectual de seu filho (BRASIL, TJSC, 2011), pelo fato de não tê-lo matriculado regularmente em rede de ensino.

Outra questão importante a ser esclarecida são os motivos que levaram o legislador a instituir a obrigação dos pais matricularem seus filhos em rede regular de ensino e os obrigarem a acompanhar sua freqüência e aproveitamento escolar.

O mero colocar na escola não afasta a responsabilidade e obrigação dos pais, uma vez que a lei atua no sentido de assegurar a permanência e a participação dos pais na evolução escolar da criança e do adolescente, analisando gradativamente seu progresso individual, incentivando para que o estudo seja-lhe um real instrumento garantidor de sua formação. 
A legitimidade jurídica de o Estado exercer com exclusividade o monopólio da prestação e fiscalização dos serviços educacionais é a primeira explicação lógica para a sistematização jurídica dos respectivos dispositivos legais.

A prestação do serviço educacional é de natureza e de interesse público, tem como objetivo o pleno desenvolvimento da pessoa, seu preparo para o exercício da cidadania e sua qualificação para o trabalho, conforme dispõe o artigo 205 da Constituição brasileira de 1988. Em razão disso, verifica-se que o Estado tem interesse e legitimidade no que tange à implantação e fiscalização das políticas públicas educacionais.

A educação dos filhos é algo que não diz respeito exclusivamente aos interesses dos pais. No direito brasileiro vigente os pais não possuem autonomia plena e exclusiva para escolherem se seus filhos estudarão ou não. A liberdade dos pais é regrada por preceitos jurídicos voltados a garantir a proteção integral dos filhos.

\section{DIREITO FUNDAMENTAL À EDUCAÇÃO E HOMESCHOOLING}

$\mathrm{Na}$ perspectiva lato sensu Educar significa transmitir conhecimentos, construir, despertar valores e estimular desafios que façam a criança e o adolescente a refletir sobre a realidade que os circundam. Segundo Regina Maria Fonseca

\footnotetext{
A educação engloba a instrução, mas é muito mais ampla. Sua finalidade é tornar os homens mais íntegros, a fim de que possam usar da técnica que receberam com sabedoria, aplicando-a disciplinadamente. Instrução e educação, embora possam ser entendidas como duas linhas paralelas com finalidades diferentes, necessariamente devem caminhar juntas e integrar-se. (MUNIZ,2002, p. 9)
}

Na acepção jurídica da palavra, a Educação é um Direito Fundamental cuja interpretação deverá ser extensiva e sistemática. Aos pais cabe o dever de criar seus filhos. Ressalta-se que criar assume a conotação jurídica de educar, no sentido mais amplo da palavra. Consiste em transmitir e possibilitar conhecimentos, despertar valores e habilitar o filho para enfrentar os desafios da vida cotidiana. Nesse sentido, a educação viabilizaria o desenvolvimento mental, moral, espiritual e social da criança e do adolescente.

$\mathrm{O}$ artigo $6^{\circ}$ da Constituição brasileira estabelece expressamente que a Educação é um Direito Social, econômico, cultural, denominado direito de segunda dimensão e garantido indistintamente a todas as pessoas. Trata-se de Direito Fundamental que determina a 
proteção da dignidade humana, bem como a construção de uma sociedade livre, justa, solidária, voltada à erradicação da pobreza, da marginalidade e redução das desigualdades sociais, tal como estabelece o artigo $3^{\circ}$ da Constituição democrática.

Além do tratamento jurídico minucioso, a grande contribuição cientifica do modelo constitucional de 1988 em relação à educação decorre de seu caráter democrático, especialmente no que atine a prioridade de estabelecer instrumentos voltados para garantir sua efetividade.

O texto constitucional de 1988, em seu artigo 208, garante a oferta do ensino fundamental a todos, estendendo-se, inclusive, a todos que não tiveram acesso na idade própria. A Educação integra o mínimo legal que o Estado pode e deve oferecer aos seus cidadãos. É uma das condições de que a pessoa humana necessita para viver de forma satisfatória a realidade a qual se encontra inserida, construindo formas de intervenção no mundo a partir de uma visão crítico-racional.

"Em relação ao direito à educação fundamental, nos parece incontroverso tratar-se de uma parcela integrante do mínimo existencial, não só por suas características intrínsecas como em razão de sua importância para a concreção de outros direitos necessários a uma existência digna" (GARCIA, 2015).

Não basta apenas garantir formalmente o direito de ir à escola, uma vez que a todos os indivíduos, indistintamente, deverá ser assegurada a possibilidade efetiva de acesso.

A Educação no Brasil é um direito público subjetivo ${ }^{6}$. Qualquer cidadão, de qualquer idade, tem garantido esse direito e poderá exigi-lo a qualquer tempo perante o poder público. Trata-se de direito social corolário da dignidade humana e imprescindível ao exercício da cidadania.

Segundo Esméria de Lourdes Saveli e Maria Odete Vieira Tenreiro "o Brasil conta, atualmente, com uma constituição guiada pelo principio da cidadania, acenando para uma perspectiva mais universalizante do direito à educação" (SAVELI; TENREIRO, 2015).

É importante esclarecer que "a educação representa tanto um mecanismo de desenvolvimento pessoal do indivíduo, como da própria sociedade em que ele se insere" (MONTEIRO, 2015).

\footnotetext{
6 Direito subjetivo público, por sua vez, é o decorrente de norma de caráter público, designativo que aufere suas características básicas no objeto da relação jurídica e na sua indisponibilidade, sendo prescindível que o Estado figure em um dos pólos do vínculo ( $v$.g.: o direito à intimidade, oponível tanto ao Estado como aos demais indivíduos) (GARCIA, 2015).
} 
Conforme estabelece o artigo 205 da Constituição brasileira de 1988 a Educação é um direito de todos e dever do Estado e da família, devendo ser promovida e incentivada com a colaboração da sociedade, visando o pleno desenvolvimento da pessoa humana, seu preparo para o exercício da cidadania e sua qualificação para o trabalho.

$\mathrm{O} \S 3^{\circ}$ do artigo 208 da Constituição estabelece que compete ao poder público a obrigação de recensear os educandos do ensino fundamental, realizando-se a chamada e zelando, juntamente com os pais ou responsáveis legais, pela frequiência escolar.

\section{A PROBLEMÁtica dA PRÁtiCA DO CRIME DE ABANDONO INTELECTUAL NO QUE CONCERNE AOS PAIS QUE PRATICAM O HOMESCHOOLING}

O descumprimento da obrigação de matricular o filho em rede de ensino tem conseqüências jurídicas no âmbito do Direito Penal. O artigo 246 do Código Penal brasileiro vigente estabelece o crime de abandono intelectual, cujo teor é o seguinte: "Deixar, sem justa causa, de prover a instrução primária de filho em idade escolar. Pena detenção, de quinze dias a um mês, ou multa”. Ressalta-se que justa causa no presente caso pode ser considerada a comprovada impossibilidade ou inviabilidade dos pais matricularem seus filhos em rede de ensino. A mera vontade e decisão livre dos pais em deixar de efetuar a matrícula dos filhos em rede regular de ensino caracteriza a prática do crime de abandono intelectual. Exclui a ilicitude condutas ou situações de miséria, pobreza, graves dificuldades financeiras, falta de vagas em estabelecimentos públicos, por exemplo, que denotam claramente que não houve omissão dolosa por parte dos pais.

\section{CONCLUSÃO}

A Educação é um Direito Fundamental de natureza personalíssima, indisponível e irrenunciável. Trata-se de direito subjetivo público cujos genitores não possuem legitimidade jurídica no que tange à limitação e a forma como esse direito será exercido pelos filhos. 
A interpretação constitucional do Direito Fundamental à Educação deverá ser feita de forma extensiva e sistemática, de modo a compreender seu entendimento jurídico pressupõe o direito da criança e do adolescente ir e freqüentar a escola.

O Estatuto da Criança e do Adolescente é categórico ao estabelecer em seus artigos 55 e 129 que constitui dever dos pais matricular seus filhos em rede de ensino, além da obrigação de acompanhar sua freqüência e aproveitamento escolar.

A Escola tem o papel de garantir ao cidadão a socialidade, sociabilidade, a formação ética e moral. Nessa seara afirma-se que os pais que optam pela educação domiciliar retiram de seus filhos o direito de escolher se querem ou não freqüentar a escola, direito esse personalíssimo e irrenunciável. Além disso, pode-se afirmar que tal prática deslegitima o Estado no que tange à prestação e a fiscalização do serviço público de educação, uma vez que o homeschooling no Brasil constitui prática pedagógica comprovadamente contrária ao Estatuto da Criança e do Adolescente e a doutrina da proteção integral.

O Homeschooling retira da criança e do adolescente a legitimidade jurídica de exercer na sua integralidade o Direito Fundamental à Educação, uma vez que são submetidos à instrução formal domiciliar imposta pelos seus genitores. Reconhecer a educação domiciliar como uma prática condizente com o direito brasileiro é o mesmo que permitir que os pais disponibilizem um direito personalíssimo de seus filhos.

Dessa forma verifica-se a inconstitucionalidade do Projeto de Lei 3179/12, por caracterizar ofensa direta à Educação, considerada um Direito Fundamental cuja titularidade é exclusiva dos filhos, não dos pais. A ilegalidade decorre do exercício abusivo do poder familiar em desconformidade com o Estatuto da Criança e do Adolescente, que determina a obrigatoriedade dos pais matricularem seus filhos em rede oficial de ensino controlada diretamente ou fiscalizada pelo poder público. Reconhecer como constitucional e legal o respectivo projeto de lei é deslegimitar o Estado em implementar políticas públicas de educação que venham a garantir a proteção integral de crianças e adolescentes. 


\section{REFERÊNCIAS}

BARBOSA, Luciane Muniz Ribeiro. ENSINO EM CASA NO BRASIL: um desafio à escola. Tese de Doutorado (Doutorado em Educação) Universidade de São Paulo, 2013.

BARBOSA, Luciane Muniz Ribeiro. Estado e educação em Martinho Lutero: a origem do direito à educação. Cadernos de Pesquisa. v. 41, n. 144, set.-dez., 2011.

BRASIL. Artigo $227 \quad d a$ Constituição de 88. Disponível em http://www.jusbrasil.com.br/topicos/10644726/artigo-227-da-constituicao-federal-de-1988.

Acesso em 27 jul. 2015.

BRASIL.Biblioteca Virtual de Direitos Humanos. Universidade de São Paulo. Disponível em http://www.direitoshumanos.usp.br/index.php/Crian\%C3\%A7a/declaracao-dos-direitos-dacrianca.html. Acesso em 23 jul. 2015.

BRASIL. Ensinar os filhos em casa ganha força no Brasil e gera polêmica. Disponível em http://www.bbc.co.uk/portuguese/noticias/2013/11/131104_educacao_domiciliar_abre_vale_ mdb. Acesso em 11 jan. 2015.

BRASIL. Life Without School. Disponível em http://lifewithoutschool.typepad.com/lifewithoutschool/2007/09/what-is-unschoo.html. Acesso em 08 jan. 2015.

BRASIL. Tribunal de Justiça de Minas Gerais. Disponível em https://dasfamilias.wordpress.com/2011/12/14/responsabilidade-civil-filiacao- abandonomaterial-moral-e-intelectual-do-pai-em-relacao-ao-filho-tratamento- anti-isonomico-entrefilhos/. .Acesso em 30 jul. 2015.

BOUDENS, Emile. Ensino em casa no Brasil. Brasília: Câmara dos Deputados, 2002.

CELETI, Filipe Rangel. Educação não obrigatória: uma discussão sobre o estado e o mercado. Dissertação (Mestrado em Educação, Arte e História da Cultura) - Universidade Presbiteriana Mackenzie, 2011.

COLBECK, James. Children'sRights In Education (In England). Studies in Philosophy and Education. v.v. 20, issue 3, p. 275-277, May 2001.

CURY, Carlos Roberto Jamil. Direito à educação: direito à igualdade, direito à diferença. Cadernos de Pesquisa, São Paulo, n. 116, p. 245-262, jul. 2002.

DIÓGENES JÚNIOR, José Eliaci Nogueira. Aspectos gerais das características dos direitos fundamentais. In: Âmbito Jurídico, Rio Grande, XV, n. 100, maio 2012. Disponível em: http://www.ambitojuridico.com.br/site/index.php/?n_link=revista_artigos_leitura\&artigo_id=1 $1749 \&$ revista_caderno=9. Acesso em 01 ago 2015.

GAITHER, Milton. Homeschool: An American History. New York: Palgrave Macmillan, 2008. 
GARCIA, Emerson. O Direito à Educação e suas Perspectivas de Efetividade. Disponível em http://www.planalto.gov.br/ccivil_03/revista/Rev_57/Artigos/Art_Emerson.htm. Acesso em 10 ago. 2015.

HERBERT, Auberon. The Right and Wrong of Compulsion by the State, and Other Essays. Indianapolis: Liberty Fund, 1978, Disponível em http://oll.libertyfund.org/titles/591. Acesso em 15 jan. 2015.

HOLT, John Caldwell. Learning all the time: how small children begin to read, write, count, and investigate the world, without being taught. Boston: Da Capo Press, 1989.

HOLT, John Caldwell. What is Unschooling? Disponível em http://translate.google.com.br/translate?hl=pt-

BR\&sl=en\&u=http://www.johnholtgws.com/frequently-asked-questions- abo/\&prev=search. Acesso em 11 jan. 2015.

ILLICH, Ivan. Sociedade sem escolas. Petrópolis: Vozes, 1973

ILLICH, Ivan. Sociedade sem escolas. Tradução Lúcia Mathilde Endlich Orth. 7. ed. Petrópolis: Vozes, 1985.

MACHADO, Martha de Toledo. A Proteção Constitucional de Crianças eAdolescentes e os Direitos Humanos. Barueri, SP. Manole. 2003.

MONTEIRO, Raquel Motta Calegari. A EDUCAÇÃO NO BRASIL: direito social e bem público. Disponível em

https://www.uniso.br/publicacoes/anais_eletronicos/2014/3_es_mercado_e_soci edade/04.pdf. Acesso em 07 jul. 2015.

MUNIZ, Regina Maria Fonseca. O Direito à Educação. Rio de Janeiro: Renovar, 2002.

RAMIREZ, Francisco O.; BOLI, John. The political construction of mas schooling european origins and worldwide institutionalization. Sociology of Education, v. 60, p. 2-17, 1987.

SACRISTÁN, José e Gomes. A Educação Obrigatória: seu sentido educativo e social. Porto Alegre: Artmed, 2001.

SAVELI, Esméria de Lourdes; TENREIRO, Maria Odete Vieira. A EDUCAÇÃO ENQUANTO DIREITO SOCIAL: aspectos históricos e constitucionais. Disponível em http://www.dtp.uem.br/rtpe/volumes/v15n2/04.pdf. Acesso em 03 ago. 2015.

SUMMERS, Ana Claudia Alexandrini. As implicações jurídicas referentes ao descumprimento do poder familiar no dever da educação de crianças e adolescentes na educação básica. Disponível em http://ambito- juridico.com.br/site/? $\mathrm{n} \_$link=revista_artigos_leitura\&artigo_id=13384\&revista_caderno=12. Acesso em 02 ago. 2015 . 
USA. What is unschooling? Disponível em http://translate.google.com.br/translate?hl=pt$\mathrm{BR} \& \mathrm{sl}=\mathrm{en} \& \mathrm{u}=\mathrm{http}: / / \mathrm{www}$. holtgws.com/whatisunschoolin.html\&prev=search. Acesso em 10 jan. 2015.

VIANA, Heloíza Souza. A Escolarização Domiciliar e seus Contrapontos. IV Encontro Estadual de Didática e Prática de Ensino. Goiás, 2011. Disponível em http://www.ceped.ueg.br/anais/ivedipe/pdfs/sociologia/co/378-844-2-SM.pdf. Acesso em 29 dez. 2014.

VIEIRA, André de Holanda Padilha. Escola? Não, obrigado: um retrato da homeschooling no Brasil. Disponível em http://bdm.unb.br/handle/10483/3946. Acesso em 18 jan. 2015. 